\title{
Numerical investigation of influence of number of stent cells and type of link on expansion and haemodynamic behaviour of balloon- expandable coronary stent
}

\author{
CHANDRAKANTHA BEKAL ${ }^{1}$, RANJAN SHETTY ${ }^{2}$ and SATISH SHENOY ${ }^{1, *}$ \\ ${ }^{1}$ Department of Aeronautical and Automobile Engineering, Manipal Institute of Technology, Manipal \\ University, Manipal, India \\ ${ }^{2}$ Department of Cardiology, Kasturba Medical College, Manipal University, Manipal, India \\ e-mail: satish.shenoy@manipal.edu
}

MS received 11 October 2016; revised 8 February 2017; accepted 25 November 2017; published online 29 May 2018

\begin{abstract}
Coronary stents are tubular, mesh-like structures used to force open clogged artery. Mounted on an inflatable balloon, stent compresses calcified plaque inside atherosclerotic artery with an inflating device, which transfers the load through the compliant balloon, thus maintaining the patency of lumen. One of the contributors for success of angioplasty is type of stents, which mainly differs in its geometrical design. A clinician recommends a stent based on comparative advantages. An ideal stent should be flexible to manoeuver through tortuous artery, easy to expand, provide good scaffolding to the vessel, have less radial recoil and foreshortening, possess uniformity in expansion and induce minimum alteration in physiological blood flow dynamics. In a stent these parameters are in competition with each other and are optimized by trade-offs. The present work tries to sequentially investigate the effect of number of stent cells and type of links on the expansion and haemodynamics behaviour through computational analysis based on finite element and finite volume techniques. The study compares performance within same classes of designs rather than comparing the designs that are completely different form each other. Results show that more number of stent cells in longitudinal direction considerably decrease the radial recoil, but increase the foreshortening effect. Restenosis-prone zones are localized around the stent struts and are predominant during end of systolic phase of cardiac cycle. Shorter links are preferred for better recoil and favourable distribution of wall shear stress while longer links are preferred for favourable foreshortening.
\end{abstract}

Keywords. Coronary stents; finite element analysis (FEA); balloon-expandable stents; in-stent restenosis.

\section{Introduction}

Stents are medical devices used to treat stenotic arteries. Stenosis are characterized by deposition of calcified plaque inside the artery, obstructing blood flow, resulting in heart pain, which is medically known as angima or Myocardial Infraction. Angioplasty with stenting is a medical solution for treating Cardiovascular Artery Disease (CAD), especially coronary artery atherosclerosis. Though the word 'stent' [1] was first used by an English dentist Charles Thomas Stent, cardiovascular stents were revolutionized in early 1980 [2]. Advances in stent design and usage have grown exponentially thereafter [3]. Statistics suggests 193,728 stents used in India for the year 2011 [4].

Stent is a tubular mesh-like structure mounted on an inflatable balloon and advanced through artery to target location with the help of a catheter. Once placed in sight it

*For correspondence is expanded to the target artery diameter by inflating the balloon by means of an external inflating device. Inflated balloon increases the diameter of stent, which undergoes plastic deformation and compresses the plaque against the wall of artery, thereby restoring uninterrupted flow of blood. Once the required lumen gain is achieved the external device deflates the balloon and is withdrawn, leaving behind the stent. The stent remains expanded with little recoil, thereby maintaining the patency of the lumen.

In spite of being an immediate clinical solution for treating the atherosclerosis, stents are not immune to drawbacks. One of the most common problems encountered is in-stent restenosis (ISR) characterized by the growth of arterial cells, or plaque through the stent struts. ISR rate as high as $68 \%$ has been reported [5]. In spite of availability of varieties and advanced stent designs [6, 7], quest for an ideal stent is an ongoing process. It has been established by researchers as well as clinicians that one of the leading factor for long-term success of the stents is their 
geometrical design [8]. It has been proved that vascular injury is a direct consequence of stent design [9]. ISR probability depends on the prevailing wall shear stress (WSS) distribution and wall shear stress gradient (WSSG) in stented artery $[10,11]$. Many researchers have tried to quantify the relation between the geometrical properties of the stent and the performance parameter such as radial recoil, WSS and wall stress to name a few [12-14]. It has been proved undoubtedly that stent design affects the immediate implantation success as well as long-term efficacy in preventing ISR.

Several studies have investigated structural and haemodynamic behaviour of stent designs. An early study numerically investigated the effect of balloon inflation on artery and its clinical significance was discussed [9]. Stent geometry is a major deciding factor on stenting outcome such as radial recoil and foreshortening effect [15]. Nonphysiological stress on native blood vessel causing arterial injury due to stent implantation is a contributor for early ISR and has been investigated in [14, 16]. A comprehensive work on finite element stent design and effect of expansion strategy was carried out by De Beule et al [17] and De Beule [18]. Supported by clinical evidences, significance of stent design parameters was comprehensively discussed in [19]. A comprehensive evaluation method for stent design was proposed with a new computational test bed for stent design [20]. Though rare, cases of stent fracture and its consequences on initiating ISR were discussed in [21]. More recent papers have sophisticatedly analysed the interaction of balloon, stent and artery during deployment [22] and inclusion of layer-specific atherosclerosis in the simulation [23] with a comprehensive review of state of art of stenting design issues [24] and microscopic assessment of stent failure probability [25].

Other predicted contributor for prevalence of ISR is alteration of WSS post-stenting. Fluid dynamic study investigated through numerical methods reveals a considerable deviation from physiological shear stress in the vicinity of stent. Many discussed the effect of stent design parameters on local haemodynamics $[10,11,26]$. Based on their study, Gundert et al [27] recommended an optimization routine based on an optimal stent design. A comprehensive study on the haemodynamics of blood flow through stented arteries was carried out by Chiastra [28] in her research work. Studies have also compared simplified Newtonian assumption with non-Newtonian analogous blood model [29]. Experimental investigation also revealed the change in the velocity and WSS distribution over the stent and the possibility of improving the geometrical design for favourable haemodynamic flow pattern was emphasized [30].

Studies discussed earlier have successfully investigated structural or haemodynamics performances of different stent designs separately and investigation was mainly concentrated on different commercial stent models. Very few cases investigated the combined structural and haemodynamics behaviour of stent design [31]. A multiobjective design optimization of stent was discussed in $[32,33]$. In all the cases discussed earlier it was either independent structural or haemodynamic study or the sequential structural and haemodynamics study on different stent designs, which are essentially replication of available commercial stents in market place.

This paper tries to investigate sequentially a few structural and haemodynamic characterizations of different parametric stents designs that fundamentally belong to the same class of designs, but differ in two fundamental parameters of stent design, namely number of stent cells and position of links. Six different stent designs with varying number of stent cells along the longitudinal direction and the position of links are investigated for structural and haemodynamic behaviour. The hypothesis that the number of cells in longitudinal direction as well as arrangement of links significantly alters structural and haemodynamic nature of the stented arteries is investigated systematically.

Stents are expanded by uniform pressure on internal surface. This structural analysis could simulate the radial recoil, longitudinal recoil and foreshortening. The expanded stent geometry is subjected to blood flow simulation to identify area of stented region subjected to critical WSS prone to restenosis. Comparative advantages and disadvantages among different designs are discussed.

\section{Methods}

\subsection{Geometry}

2.1a Stent geometry: Stent is a tubular mesh-like structure made up of materials like stainless steel (AISL316L) or nickel titanium alloy (Nitinol) or cobalt chromium alloy, etc. [34]. Though hundreds of different designs are available in the market, all the varieties share common features of 'cell' or 'strut' and 'link' or the 'bridge'. Stent cells undergo plastic deformation during the expansion and function as scaffolds for the artery, whereas link is a connection between stent cells and is responsible for imparting flexibility. Stent cells and links repeatedly placed in circumferential and longitudinal directions form a complete stent. A typical stent unit (cell and link) and complete stent cell geometry in planar form is shown in figure 1.

Geometry of a crimped stent is modelled using commercial modelling package SolidWorks 2014 (Dassault systemes). Representative dimensions of a stent wire are obtained by photographing the commercial stent Resolute Integrity (Medtronic Inc.) using a high-resolution scanning electron microscope (SEM). Based on the photographs, the stent thickness is taken as $100 \mu \mathrm{m}(0.1 \mathrm{~mm})$. A stent cell and link is sketched in a plane and repeated in circumferential and longitudinal directions to construct planar stent geometry. Taking advantage of geometrical symmetry, only 


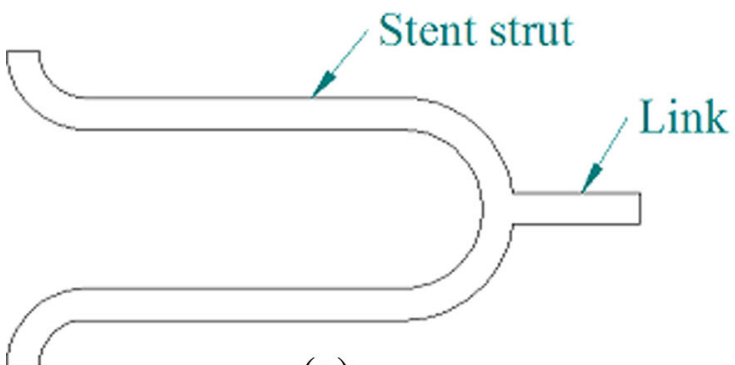

(a)

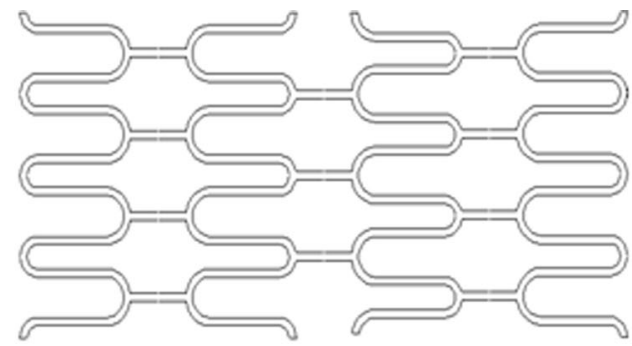

(b)

Figure 1. (a) A stent unit made up of stent cell (strut) and link. (b) Planar stent geometry.

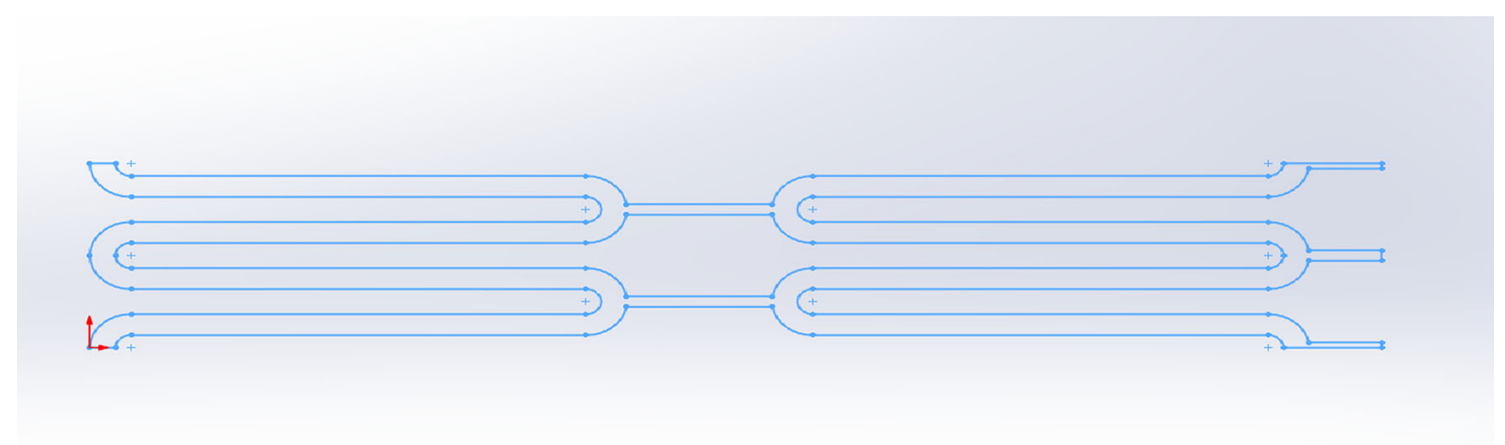

Figure 2. Planar stent geometry $(4 \mathrm{~S})$.

a quarter ring in circumferential direction and half stent in longitudinal direction is sketched. This sketch is wrapped around the cylinder to form a quarter-ring half-stent threedimensional model. A 2D planar sketch of quarter-ring half-stent (figure 2), wrapped stent cell is shown in figure 3. Quarter-ring half-stent is mirrored about the plane of symmetry, which results in the full stent as shown in figure 4. The final stent geometry with total length of $10.1 \mathrm{~mm}$, inside diameter of $1.12 \mathrm{~mm}$ with external diameter of $1.32 \mathrm{~mm}$ is obtained.

Six different designs are obtained with different combinations of number of cells and types of links. The number of cells in circumferential direction is kept constant at eight for all the stents designs. Six models are designated as $4 \mathrm{~S}$, $6 \mathrm{~S}, 8 \mathrm{~S}, 4 \mathrm{~L}, 6 \mathrm{~L}$ and $8 \mathrm{~L}$ where numbers 4,6 and 8 represent the number of cells in longitudinal direction and $\mathrm{S}$ and $\mathrm{L}$ stand, respectively, for short link and long link. Table 1 summarizes the dimensions and other details of all the stent designs.

All six varieties of stent design are shown in figure 5.

A similar method is used to construct expanded stent geometry used for blood flow simulation. Inside diameter of $3 \mathrm{~mm}$ and a foreshortening of $10 \%$ is assumed. Figure 6 shows an expanded geometry of the stent $(6 S)$.

2.1b Fluid domain geometry: The fluid domain of stented artery essentially consists of space occupied by blood.
Blood flows through highly tortuous complex coronary artery in reality. For computational convenience the coronary artery is assumed to be made up of straight cylinders. The diameter of the coronary artery ranges from 1 to $5 \mathrm{~mm}$ [35]. As a representative case a lumen diameter of $3 \mathrm{~mm}$ is assumed. To accommodate the unstented portion of the artery a length of $2 \mathrm{~mm}$ is added at both proximal and distal ends. The blood domain of stented region is constructed by Boolean subtraction of stent geometry from the coronary artery geometry, which is constructed as a straight cylinder. Final stented artery blood domain is as shown in figure 7. Assuming a symmetrical blood flow, only a quarter portion of the domain is used for simulation to reduce computational cost.

\subsection{Material}

2.2a Stent: Balloon-expandable stents are typically made up of medical grade stainless steel (AISL316L). Mechanical properties of the stent material are size dependent [36]. For computational convenience, Young' modulus, Poison's ratio, yield strength and tangent modulus of the stainless steel are used for analysis. Different researchers have used different values that are in close agreement with each other $[15,22,37]$. Table 2 summarizes the material description. 


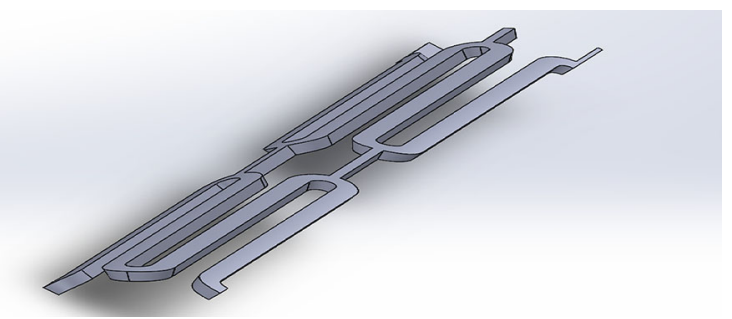

Figure 3. Half-ring, quarter portion of stent $4 \mathrm{~S}$.

2.2b Blood property: Blood is a non-Newtonian fluid. Researchers suggest that at high shear rate blood behaves as a Newtonian fluid [38]. Many researchers used Newtonian assumptions in their investigation [39, 40]. Though nonNewtonian and Newtonian assumptions produced conflicting result experimentally [29], Newtonian assumption is computationally viable. Density of $1060 \mathrm{~kg} / \mathrm{m}^{3}$ and dynamic viscosity of $0.0035 \mathrm{~Pa}$ is assumed based on past studies [39, 40].

\subsection{Characterization of performance}

To quantify structural expansion of the stent, several performance parameters are identified based on the past studies $[18,41]$. These parameters and their description with the significance of each term relevant for an angioplasty procedure is given here:

radial recoil $=\frac{\operatorname{radius}(\text { average })(\text { load })-\operatorname{radius}(\text { average })(\text { unload })}{\text { radius }(\text { average })(\text { load })}$,

longitudinal recoil $=\frac{\text { length }(\text { load })-\text { length }(\text { unload })}{\text { length }(\text { load })}$,

$$
\text { foreshortening }=\frac{\text { length }(\text { befor load })-\text { length }(\text { unload })}{\text { length }(\text { before load })},
$$

$$
\operatorname{dog} \text { bonnning }=\frac{\operatorname{radius}(\operatorname{distal})-\operatorname{radius}(\text { central })}{\operatorname{radius}(\operatorname{distal})}
$$

\begin{tabular}{|c|c|c|c|}
\hline Stent & $\begin{array}{l}\text { Number of cells in } \\
\text { longitudinal direction }\end{array}$ & $\begin{array}{l}\text { Type of } \\
\text { link }\end{array}$ & $\begin{array}{l}\text { Length of cell } \\
\qquad(\mathrm{mm})\end{array}$ \\
\hline $4 S$ & 4 & $\begin{array}{r}\text { Peak to } \\
\text { peak }\end{array}$ & 2.10 \\
\hline $6 \mathrm{~S}$ & 6 & $\begin{array}{r}\text { Peak to } \\
\text { peak }\end{array}$ & 1.21 \\
\hline $8 \mathrm{~S}$ & 8 & $\begin{array}{r}\text { Peak to } \\
\text { peak }\end{array}$ & 0.77 \\
\hline $4 \mathrm{~L}$ & 4 & $\begin{array}{c}\text { Valley to } \\
\text { valley }\end{array}$ & 2.10 \\
\hline $6 \mathrm{~L}$ & 6 & $\begin{array}{c}\text { Valley to } \\
\text { valley }\end{array}$ & 1.21 \\
\hline $8 \mathrm{~L}$ & 8 & $\begin{array}{c}\text { Valley to } \\
\text { valley }\end{array}$ & 0.77 \\
\hline
\end{tabular}

Table 1. Specifications of stent geometries.

Haemodynamic behaviour is characterized by WSS, WSSG and Oscillatory Shear Index (OSI) [29]. All these parameters are defined here [28]:WSS $(\tau)$

$$
\tau=t . \tau i j
$$

where $t$ is tangential vector to the arterial surface and $\tau i j$ is viscous stress tensor.

$$
\begin{gathered}
W S S G=\sqrt{\left(\frac{\partial \tau}{\partial x}\right)^{2}+\left(\frac{\partial \tau}{\partial y}\right)^{2}} \\
O S I=1 / 2\left(1-\left(\left|\int_{0}^{T} \tau d t\right| / \int_{0}^{T}|\tau| d t\right)\right) .
\end{gathered}
$$

Literature suggests that restenosis-prone regions are those exposed to a lower WSS (less than 0.5 Pa) [42] and these regions are also susceptible to endothelium distortion [28]. Hence we chose to identify the concerned region around the stented portion. Percentage area exposed to WSS ( $x$ direction) less than $0.5 \mathrm{~Pa}$ and area with recirculation (negative WSS) are identified spatially and temporally.

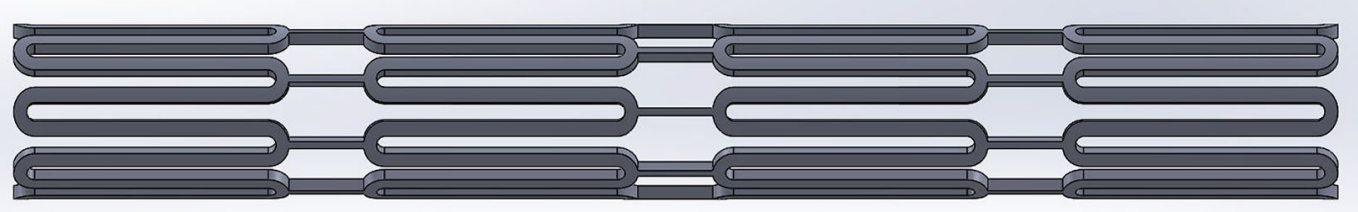

Figure 4. Full stent $4 \mathrm{~S}$. 


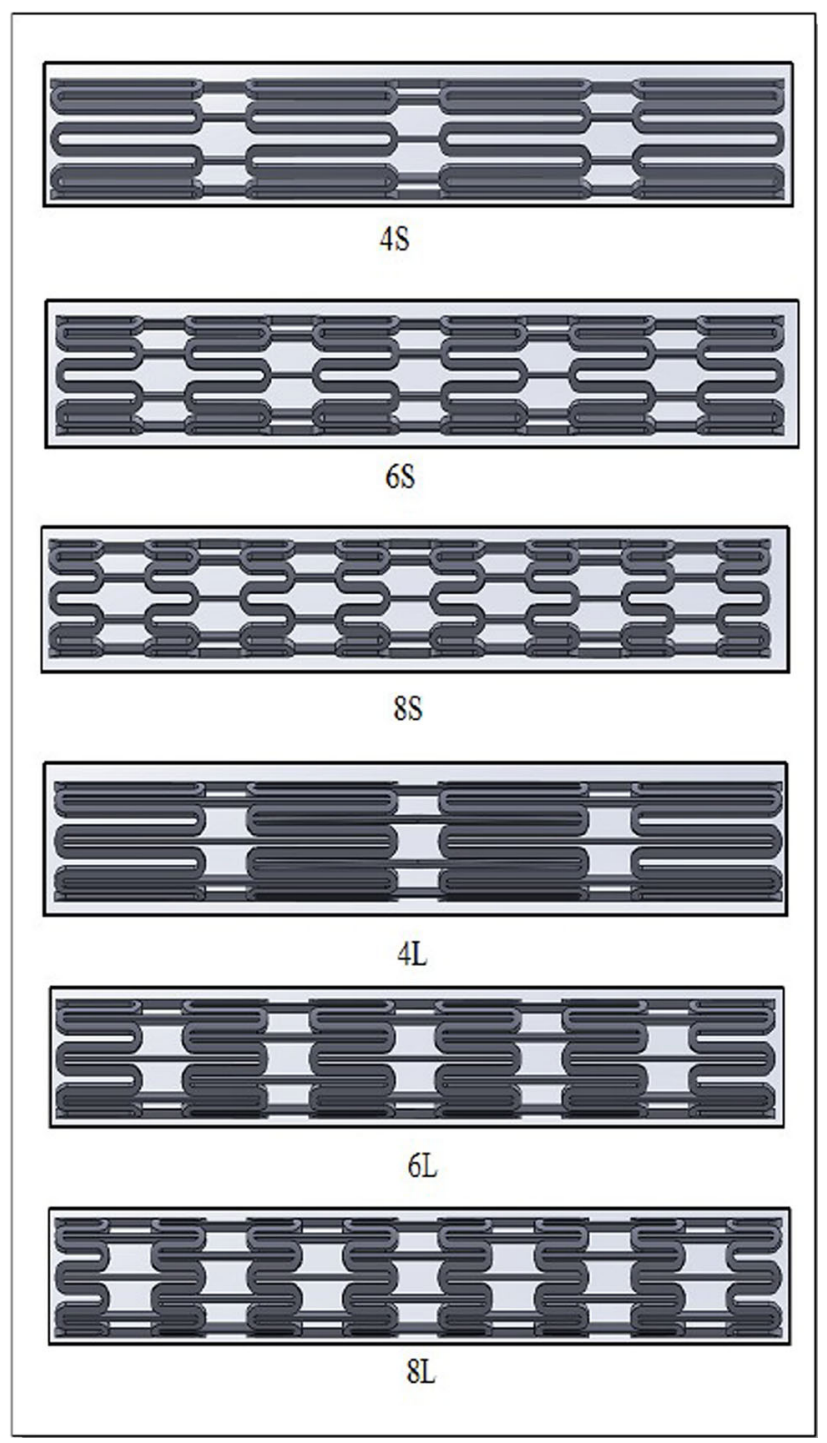

Figure 5. All six varieties of stent geometry.

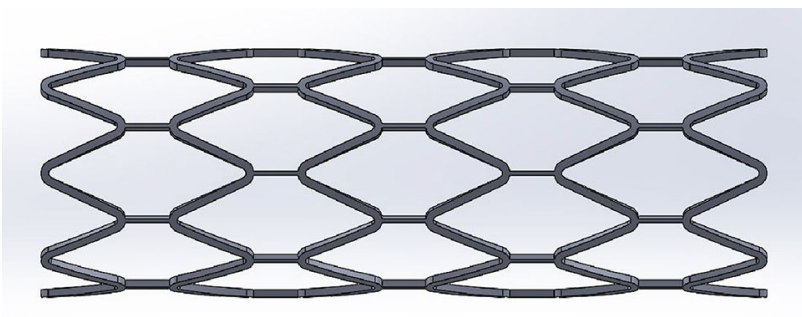

Figure 6. Expanded stent geometry (6S).

\subsection{Velocity waveform}

Blood flow is pulsatile in nature. This transient nature of flow is brought about by pumping action of heart. A healthy heart beats on average 72 times per minute, producing a cardiac cycle of $0.8 \mathrm{~s}$. Experimental measurement of centreline velocity and pressure of blood flow through left anterior descending artery (LAD) produced a time-varying velocity and pressure waveforms [43]. For the computational study, many researchers have used similar velocity waveforms [10, 44]. The present study uses a velocity waveform depicted in figure 8, adapted from [45] with uniform velocity profile across the section.

Data from this are extracted and replication is done with possible accuracy (figure 9) for subsequent usage in the flow simulation.

\subsection{Simulation}

Commercial FEA package ANSYS Workbench 16.2 (ANSYS Academic Research) is used for simulation. Expansion simulation uses static structural module and blood flow simulation is carried out using fluid flow CFX module.

2.5a Expansion: Radial pressure on internal surface of stent simulates the expansion. In the first load step, a uniform pressure is applied normal to the stent internal surface in outward direction. In the second step, pressure is reduced to zero uniformly to mimic the balloon deflation. Large-deformation analysis is used to handle nonlinear plastic deformation of the stent during expansion. On all planes of symmetry, frictionless support boundary condition is used. This ensures the restriction of rigid body motion as well. Mesh sensitivity analysis ensured that the results are independent of number of elements. Three meshes with sizes $0.05,0.025$ and $0.0125 \mathrm{~mm}$ used for the purpose. A summary of analysis shows that difference in maximum Von Mises stress (VMS)/radial displacement progressively drops between successive mesh and falls below 5\% between mesh size 0.025 and 0.0125. Subsequently, 0.0125 -mm-sized elements are used. Hexahedron or brick element is selected for meshing the model for faster convergence $[32,46]$. A radial outward pressure starting from 0.9 to 15.2 bar is applied for expansion. This range is selected based on the requirement that stent attains an outside diameter of approximately $3 \mathrm{~mm}$ upon expansion, which is typical of a coronary stent. These ranges are consistent with the pressure required for expanding commercial stents in practice [15, 17].

2.5b Blood flow: Transient blood flow is simulated with pulsatile velocity at the inlet of blood domain. Simulation is carried out for 0.8 (one cardiac cycle) s with a time step of $0.05 \mathrm{~s}$ based on past study [47]. At the outlet, zero static pressure is assumed [48]. A laminar fluid model is used for the simulation. Reference pressure is assumed to be $1 \mathrm{~atm}$. No-slip boundary condition is assumed on the boundary of the domain. Symmetry boundary conditions are applied at all symmetrical planes. Areas subjected to $\mathrm{WSS}_{x}<0.5 \mathrm{~Pa}$ and $\mathrm{WSS}_{\mathrm{x}}<0$ are identified at different time intervals after simulation. 


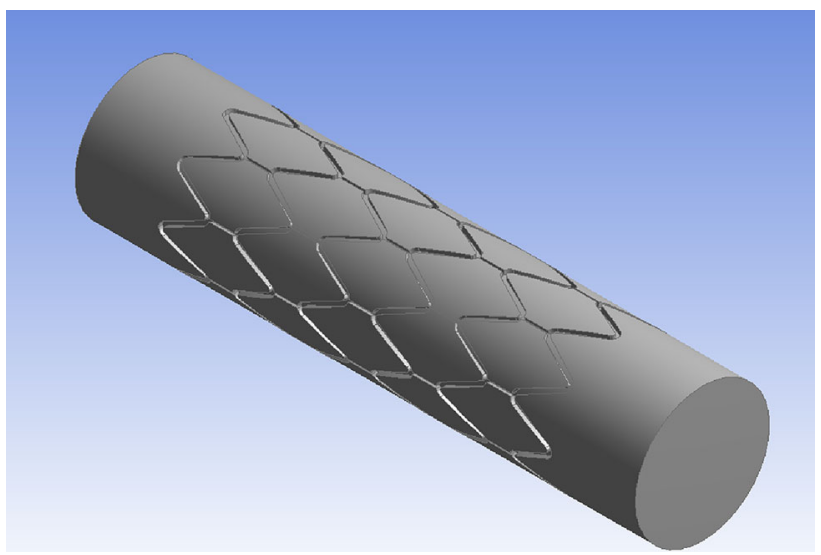

Figure 7. Stented artery blood domain (6S).

Table 2. Stent material properties.

\begin{tabular}{lccccc}
\hline Material & $\begin{array}{c}\text { Young's } \\
\text { modulus }\end{array}$ & $\begin{array}{c}\text { Yield } \\
\text { strength }\end{array}$ & $\begin{array}{c}\text { Poison's } \\
\text { ratio }\end{array}$ & $\begin{array}{c}\text { Tangent } \\
\text { modulus }\end{array}$ & Density \\
\hline $\begin{array}{c}\text { Stainless } \\
\text { steel }\end{array}$ & $196 \mathrm{GPa}$ & $205 \mathrm{MPa}$ & 0.3 & $692 \mathrm{MPa}$ & $\begin{array}{c}7850 \mathrm{~kg} / \\
\mathrm{m}^{3}\end{array}$ \\
\hline
\end{tabular}

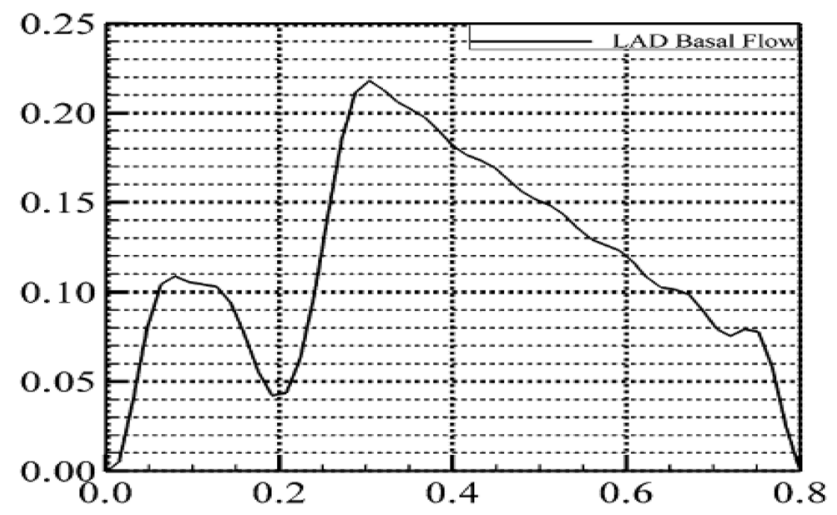

Figure 8. Centreline blood velocity waveform through LAD.

A steady-state simulation with inlet velocity of $0.2 \mathrm{~m} / \mathrm{s}$ is used for mesh sensitivity analysis. Since the objective was to capture the WSS, which is wall phenomenon, mesh is refined at the outside surface of the domain instead of whole domain. This ensures that computational cost is reduced without compromising on the result. Further, refinement of mesh is done in the vicinity of the wall. A summary of mesh sensitivity test is presented in table 3 .

As can be noticed, the difference in the area subjected to $\mathrm{WSS}_{x}$ less than $0.5 \mathrm{~Pa}$ between two mesh types 3 and 4 is $0.53 \%$. Based on this, mesh size of $0.0125 \mathrm{~mm}$ with inflation layer 10 is selected for simulations.

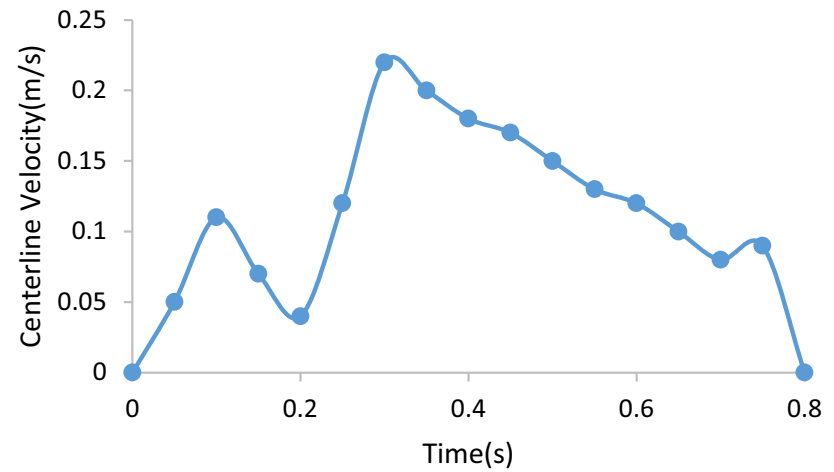

Figure 9. Centreline blood velocity waveform used for simulation.

Table 3. Summary of mesh sensitivity analysis.

\begin{tabular}{|c|c|c|c|c|c|}
\hline Type & $\begin{array}{c}\text { Surface } \\
\text { mesh } \\
\text { size } \\
(\mathrm{mm})\end{array}$ & $\begin{array}{c}\text { Inflation } \\
\text { layer }\end{array}$ & Nodes & Elements & $\begin{array}{l}\text { Area with } \\
\mathrm{WSS}_{x}<0.5 \\
\mathrm{~Pa}\left(\mathrm{~mm}^{2}\right)\end{array}$ \\
\hline 1 & 0.025 & - & 320073 & 1666753 & 40.34 \\
\hline 2 & 0.0125 & 5 & 2486136 & 81184354 & 50.00 \\
\hline 3 & 0.0125 & 10 & 3895763 & 10832281 & 51.14 \\
\hline 4 & 0.0125 & 20 & 6810486 & 16685524 & 51.41 \\
\hline
\end{tabular}

\section{Results and discussion}

The following section presents and discusses the result of expansion and blood flow simulations of six varieties of stent geometry.

\subsection{Expansion}

Figure 10 depicts the variation of maximum VMS and maximum radial displacement in one of the stents during the deployment. It can be observed that the maximum VMS increases sharply during the initial loading stage with negligible displacement. When sufficient stress builds up, the stent expands rapidly till loading and a recoil of stent is observed upon the removal of load. Length of the stent reduces as a result of increase of diameter, resulting in foreshortening effect. It is interesting to note that major contributor to this foreshortening is stent cell while link remains nearly unchanged in its length. Though longitudinal recoil is also observed, the magnitude is negligible.

A similar trend is observed in all varieties of stents investigated. A summary of the parameters of interest is tabulated in table 4 for all stent designs.

Results indicate dependence of pressure required to expand the stent to a given diameter on number of cells in longitudinal direction. A higher number of stent cells 


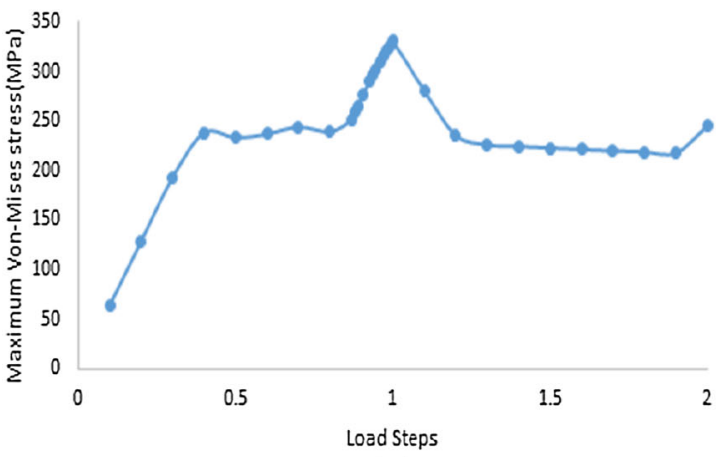

(a)

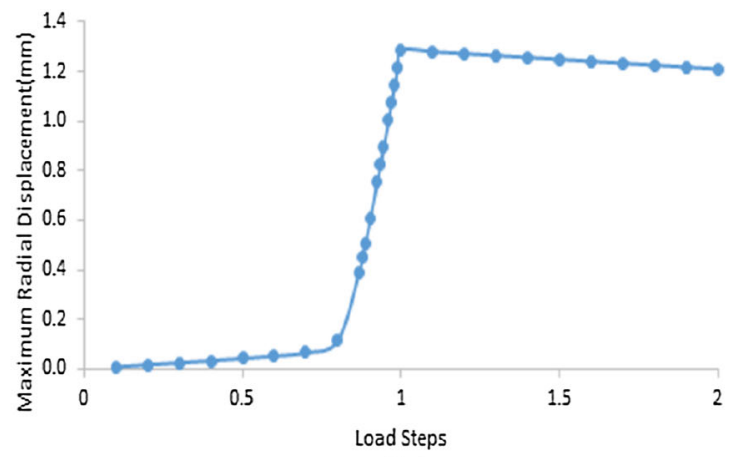

(b)

Figure 10. (a) Variation of maximum VMS and (b) maximum radial displacement.

Table 4. Consolidated results of expansion simulations.

\begin{tabular}{lccccc}
\hline Type of stent & $\begin{array}{c}\text { Pressure required } \\
(\mathrm{MPa})\end{array}$ & Internal surface area $\left(\mathrm{mm}^{2}\right)$ & Radial recoil (\%) & \multicolumn{2}{c}{ Longitudinal recoil $(\%)$} \\
\hline 4S & 0.12 & 1.79 & 3.13 & 0.29 & -3.03 \\
6S & 0.42 & 1.63 & 1.98 & 0.28 & -6.88 \\
8S & 1.52 & 1.46 & 0.73 & 0.32 & -16.43 \\
4L & 0.09 & 2.38 & 4.77 & 0.13 & -0.72 \\
6L & 0.31 & 2.18 & 2.65 & 0.19 & -3.59 \\
8L & 1.2 & 1.93 & 1.03 & 0.26 & -12.38 \\
\hline
\end{tabular}

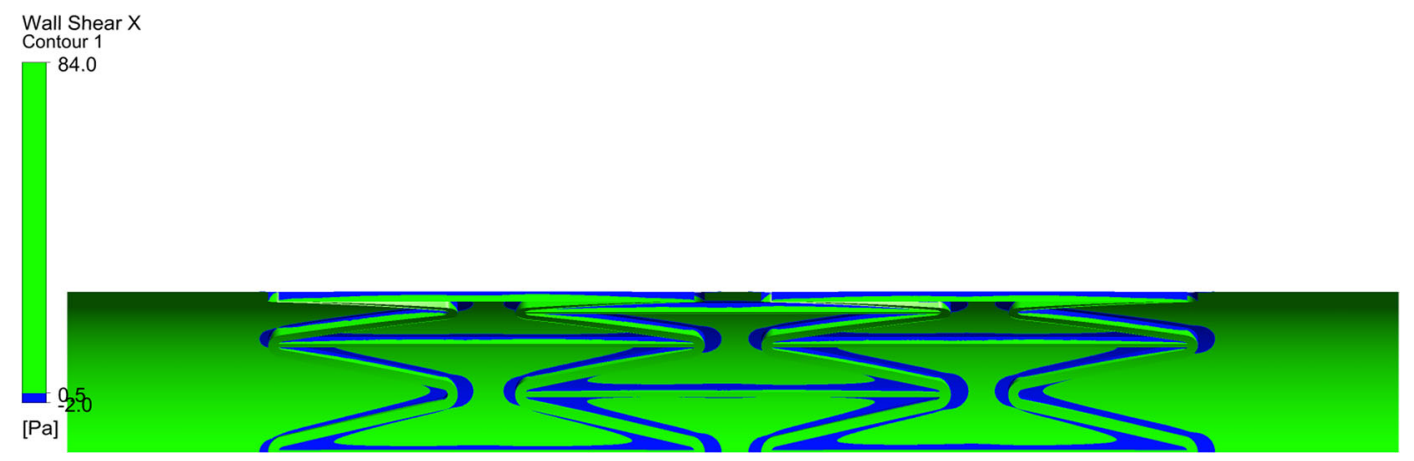

Figure 11. WSS distribution around stent struts.

require more pressure for expansion, a factor of concern for clinicians, as higher pressure may result in more arterial injury. Interestingly a decrease of $9 \%$ (between $4 \mathrm{~S}$ and $6 \mathrm{~S}$ ) internal surface area of stent resulted in $250 \%$ increase in the pressure required for expansion, thus indicating sensitivity of pressure requirement for variation of stent surface area. On the other hand, radial recoil, a major concern for effective stenting, is observed to decrease with increase in stent cells at the expense of increase in foreshortening for stent with shorter links. These quantities agree with findings of previous studies [41, 46, 49]. For stents with longer links, the pressure required for expansion was comparatively lower than those with shorter links.

\subsection{Fluid flow}

Spatial and temporal distribution of $\mathrm{WSS}_{x}$ is identified for all stent geometries. Figure 11 shows $\mathrm{WSS}_{x}$ distribution for one of the stent designs (4L) at time steps of $0.5 \mathrm{~s}$. The blue coloured band signifies the area subjected to $\mathrm{WSS}_{x}<0.5 \mathrm{~Pa}$. These concerned areas are localized around the stent strut.

Literature suggests that the region exposed to $\mathrm{WSS}_{x}$ less than $0.5 \mathrm{~Pa}$ is more prone to restenosis and endothelium distortion. A negative $\mathrm{WSS}_{x}$ indicates that flow reversal can be observed close to stent struts. Figure 12 shows percentage (fraction of total stented area) area with 
WSS $x<0.5 \mathrm{~Pa}$

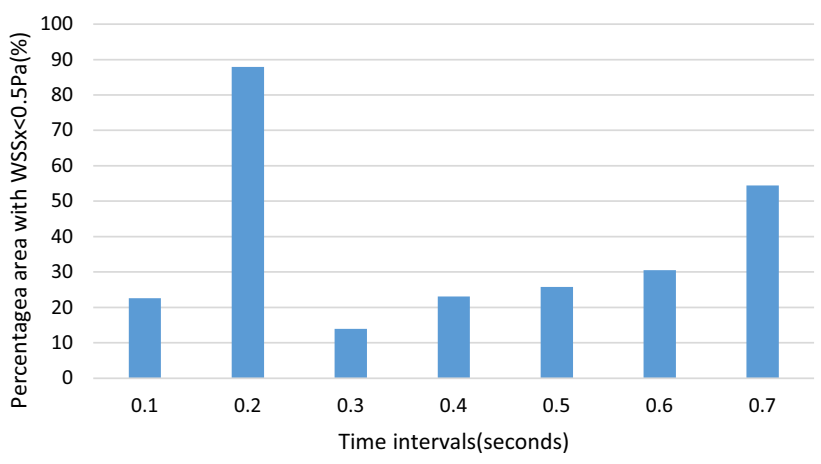

Figure 12. Percentage area with $\mathrm{WSS}_{x}$ less than $0.5 \mathrm{~Pa}(4 \mathrm{~L})$.

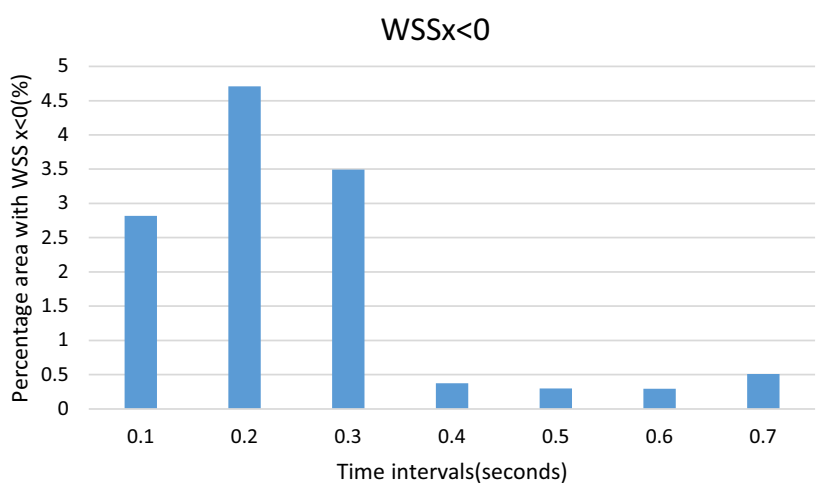

Figure 13. Percentage area with $\mathrm{WSS}_{x}$ less than $0 \mathrm{~Pa}(4 \mathrm{~L})$.

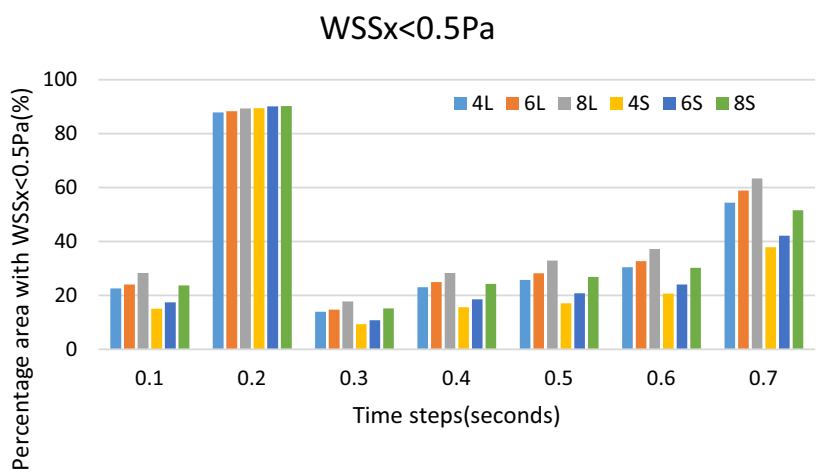

Figure 14. Comparisons of percentage area with $\mathrm{WSS}_{x}$ less than $0.5 \mathrm{~Pa}(4 \mathrm{~L})$.

$\mathrm{WSS}_{x}<0.5 \mathrm{~Pa}$ for stent $4 \mathrm{~L}$ at selected time intervals during the cardiac cycle. It can be observed that larger region is exposed to threshold $\mathrm{WSS}_{x}$ at the end of systolic phase of cardiac cycle.

Figure 13 shows the percentage area with $\mathrm{WSS}_{x}<0$ in stented arteries during the cardiac cycle.

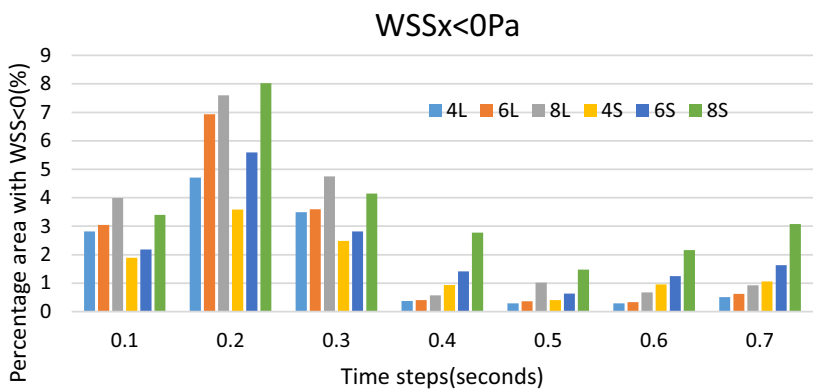

Figure 15. Comparisons of percentage area with $\mathrm{WSS}_{x}$ less than $0 \mathrm{~Pa}(4 \mathrm{~L})$.

Table 5. Independent and dependent variables involved in analysis.

\begin{tabular}{lc}
\hline Independent variable & Dependent variable \\
\hline $\begin{array}{l}\text { 1. Number of stent cells } \\
\text { (four, six and eight) }\end{array}$ & 1. Radial recoil (RR) \\
$\begin{array}{l}\text { 2. Type of links (short and } \\
\text { long) }\end{array}$ & 2. Foreshortening (FS) \\
& \\
& 3. Pressure required (PR) \\
4. Percentage area with \\
WSS $<0.5$ Pa (WSS0 $<0.5)$ \\
5. Percentage area with WSS $<0$ \\
(WSS $<0)$ \\
\hline
\end{tabular}

Table 6. Results of structural and fluid flow analysis.

\begin{tabular}{lrr}
\hline & Short & Long \\
\hline Radial recoil (RR) $(\%)$ & 3.13 & \\
Four & 1.98 & 4.77 \\
Six & 0.73 & 2.65 \\
Eight & & 1.03 \\
Foreshortening (FS) (\%) & \\
Four & 3.03 & 0.72 \\
Six & 6.881 & 3.59 \\
Eight & 16.43 & 12.38 \\
Pressure required (PR) $(\mathrm{MPa})$ & \\
Four & 0.12 & 0.09 \\
Six & 0.42 & 0.31 \\
Eight & 1.52 & 1.20 \\
Area with $\mathrm{WSS}_{x}<0.5 \mathrm{~Pa}(\%)$ & \\
Four & 29.33 & 36.89 \\
Six & 31.98 & 38.85 \\
Eight & 37.45 & 42.49 \\
Area with $\mathrm{WSS}_{x}<0 \mathrm{~Pa}(\%)$ & \\
Four & 1.62 & 1.78 \\
Six & 2.22 & 2.18 \\
Eight & 3.58 & 2.79 \\
\hline
\end{tabular}

During the end of systolic phase of cardiac cycle, more area is subjected to reverse flow, thus making it severely prone to restenosis. 
RR

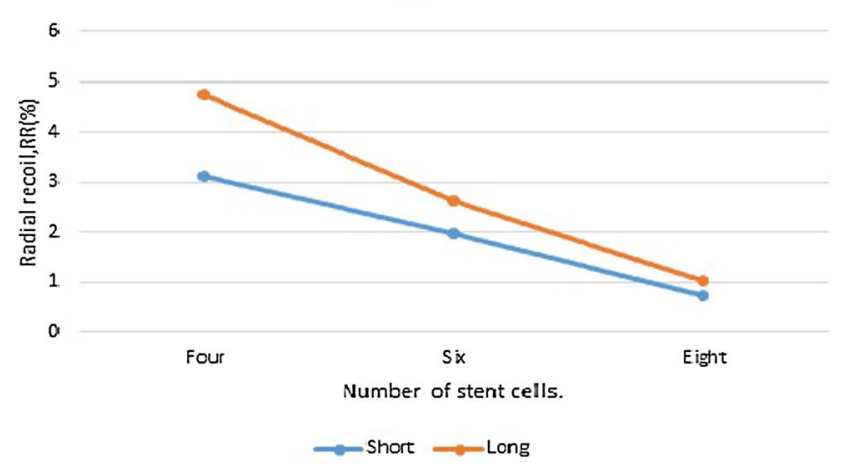

PR

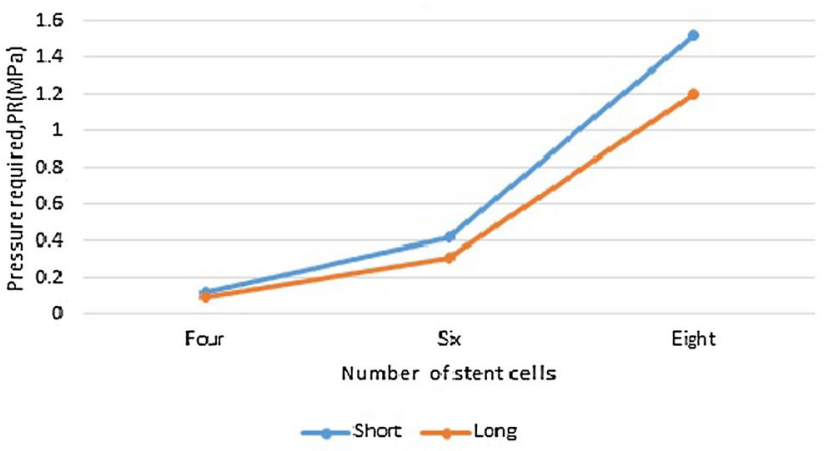

FS

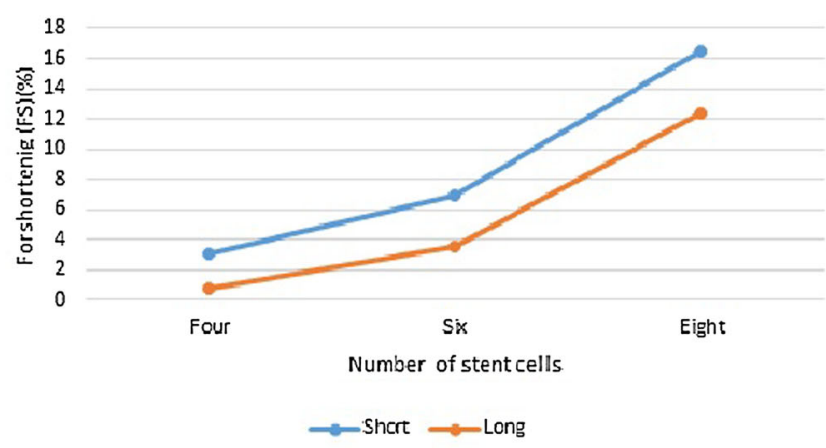

WSS $<0.5 \mathrm{~Pa}$

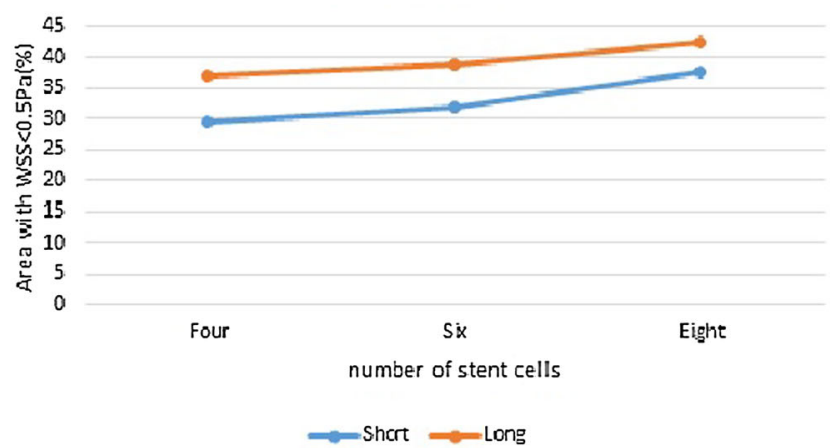

WSSEOPa

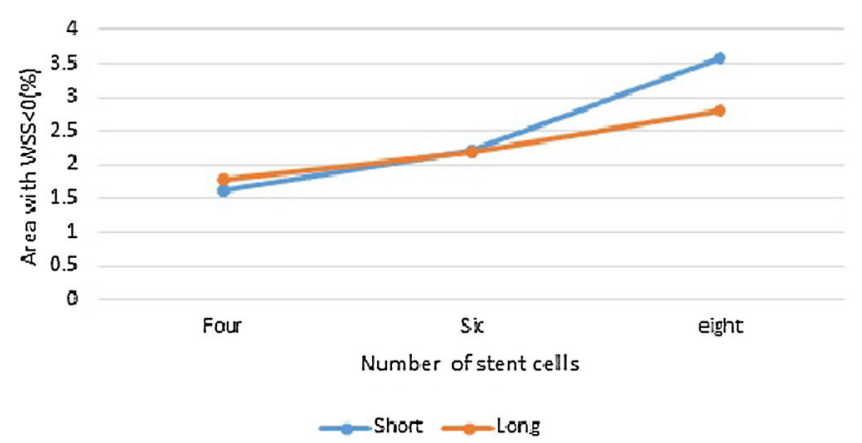

Figure 16. Comparison of performance parameters.

Figures 14 and 15 present these two results for all varieties of stents investigated.

Comparisons of these results signify a finding that larger link produces more restenosis-prone area during major part of cardiac cycle. Interestingly, at the end of systolic phase all the designs show a similar result as far as $\mathrm{WSS}_{x}<0.5 \mathrm{~Pa}$ is concerned. Increase of stent cells in longitudinal direction resulted in more area subjected to $\mathrm{WSS}_{x}<0.5 \mathrm{~Pa}$ for all the varieties.

Similar results are obtained for the area subjected to $\mathrm{WSS}_{x}<0$ (figure 15). Though quantitatively the percentage area is small in comparison with that of $\mathrm{WSS}_{x}<0.5 \mathrm{~Pa}$, it is highly appreciable to take notice of the fact that cyclic flow reversal may probably cause stent migration. From this it can be conveniently concluded that the major concern is end systolic phase, during which larger areas are exposed to critical values of WSS. Interestingly, stent $8 \mathrm{~S}$ produced larger area subjected to flow reversal compared with all other varieties during all stages of cardiac cycle. These trends observed here qualitatively agree with those of [10].

\subsection{Comparisons of performance parameters}

Tables 5 and 6 and figure 16 summarize the performance parameters for comparison. 


\section{Conclusion, limitations and scope for future work}

This study proposes a comparative study to evaluate the effect of number of cells and type of link on a few performance parameters of stent. The significance of effect of each design parameter on the performance is evaluated. Results show that the radial recoil of the stent depends on the number of stent cells. Radial recoil decreases considerably at higher number of cells as a result of higher plastic strain induced. At smaller number of cells this difference is appreciable between short link and long link but difference reduces at higher number of cells. A stent with shorter link but larger number of cells is preferred for favourable expansion as this induces less radial recoil, thus avoiding ever expansion of stent, which may result in undesirable, non-physiological stress on artery. Also peak to peak connection (shorter link) reduces the protrusion of stent struts onto artery (due to uniform expansion) in comparison with longer link stents. Foreshortening effect is found to increase with number of cells and this may be a direct consequence of lesser radial recoil. Longer link is comparatively preferred for favourable foreshortening effect as it remained low for different numbers of cells. A higher foreshortening may require lengthier stent being used, which may put unnecessary stress on healthy artery. At lower number of cells the pressure required to expand a given stent differed negligibly and difference was appreciable at higher number of cells. Results indicate that lower the internal surface area, more the pressure requirement to deploy the stent. This result signifies the sensitivity of pressure required to expand the internal surface area of the stent, a major concern for the clinicians, as higher pressure may lead to higher arterial injury. As far as flow disturbance is considered, the more restenosis-prone zone is localized around the stent struts during the systolic phase of cardiac cycle. Shorter link produced comparatively less restenosis-prone zone as a result of lesser metal surface area exposed to blood flow. Recirculation zone is found to be maximum for stent with shorter link and more number of cells as change of direction of flow is much often in this case. An overall comparison of the results suggests that the performance parameters are in competition with each other and a suitable trade-off is necessary.

The present work investigated the effect of only two of many design variables that could affect the performance of a stent. More robust parameterization techniques for investigating the effects of other variables of interest should be considered for generalization of these results. Realistic expansion of the stent involves a balloon to expand the stent where a more sophisticated contact nature of stent and balloon material should be considered. This work neglected the presence of balloon for the sake of simplicity of simulation. This is the main limitation of present work. However, these results are useful for parametric comparison. A more complex stent and artery interaction is avoided for economy of simulation. Highly sophisticated, anisotropic, layerspecific material model of artery can provide better quantification of effect of variables on the performance. Flow is assumed to be laminar, of constant density, incompressible and Newtonian in nature. Effect of more sophisticated turbulent, non-Newtonian models of blood flow will provide better flow characterization. In addition to expansion and flow, more variables such as flexibility, drug delivery, etc. can be simulated for better design. No human/animal studies were carried out by the authors for this article.

\section{References}

[1] Roguin A 2011 Stent: the man and word behind the coronary metal prosthesis. Circ. Cardiovasc. Interv. 4(2): 206-209

[2] Rösch J, Keller F S and Kaufman J A 2003 The birth, early years, and future of interventional radiology. J. Vasc. Interv. Radiol. 14(7): 841-853

[3] Foerst J, Vorpahl M, Engelhardt M, Koehler T, Tiroch K and Wessely R 2013 Evolution of coronary stents: from baremetal stents to fully biodegradable, drug-eluting stents. Comb. Prod. Ther. 3: 9-24

[4] Ramakrishnan S, Mishra S, Chakraborty R, Sarat Chandra K and Mardikar H M 2013 The report on the Indian coronary intervention data for the year 2011 e National Interventional Council. Indian Heart J. 65(5): 518-521

[5] Garg S and Serruys P W 2010 Coronary stents: current status. J. Am. Coll. Cardiol. 56(10 suppl): S1-S42

[6] Whittaker D R and Fillinger M F 2006 The engineering of endovascular stent technology: a review. Vasc. Endovasc. Surg. 40(2): 85-94

[7] Garg S and Serruys P W 2010 Coronary stents: looking forward. J. Am. Coll. Cardiol. 56(10 suppl): S43-S78

[8] Timmins L H, Miller M W, Clubb F J and Moore J E 2011 Increased artery wall stress post-stenting leads to greater intimal thickening. Lab. Invest. 91(6): 955-967

[9] Rogers C, Tseng D Y, Squire J C and Edelman E R 1999 Balloon-artery interactions during stent placement: a finite element analysis approach to pressure, compliance, and stent design as contributors to vascular injury. Circ. Res. 84(4): 378-383

[10] Balossino R, Gervaso F, Migliavacca F and Dubini G 2008 Effects of different stent designs on local hemodynamics in stented arteries. J. Biomech. 41(5): 1053-1061

[11] Morlacchi S, Keller B, Arcangeli P, Balzan M, Migliavacca F, Dubini G, Gunn J, Arnold N, Narracott A, Evans D and Lawford P 2011 Hemodynamics and in-stent restenosis: micro-CT images, histology, and computer simulations. Ann. Biomed. Eng. 39(10): 2615-2626

[12] Shen X, Yi H and Ni Z 2008 Effects of stent design parameters on radial force of stent. In: Proceedings of the 2nd International Conference on Bioinformatics and Biomedical Engineering, iCBBE 2008, vol. 1, pp. 1712-1716

[13] Zhao S, Gu L and Froemming S R 2012 On the importance of modeling stent procedure for predicting arterial mechanics. J. Biomech. Eng. 134(12): 121005 
[14] Bedoya J, Meyer C A, Timmins L H, Moreno M R and Moore J E 2006 Effects of stent design parameters on normal artery wall mechanics. J. Biomech. Eng. 128(5): 757-765

[15] Migliavacca F, Petrini L, Colombo M, Auricchio F and Pietrabissa R 2002 Mechanical behavior of coronary stents investigated through the finite element method. J. Biomech. 35(6): 803-811

[16] Lally C, Dolan F and Prendergast P J 2005 Cardiovascular stent design and vessel stresses: a finite element analysis. $J$. Biomech. 38(8): 1574-1581

[17] De Beule M, Mortier P, Carlier S G, Verhegghe B, Van Impe R and Verdonck P 2008 Realistic finite element-based stent design: the impact of balloon folding. J. Biomech. 41(2): 383-389

[18] De Beule M 2008 Design van stents met eindige elementenfinite element stent design. Ph.D. thesis, Univeristy of Gent, Belgium.

[19] Siewiorek G M, Finol E A and Wholey M H 2009 Clinical significance and technical assessment of stent cell geometry in carotid artery stenting. J. Endovasc. Ther. 16: 178-188

[20] Conway C, Sharif F, McGarry J P and McHugh P E 2012 A computational test-bed to assess coronary stent implantation mechanics using a population-specific approach. Cardiovasc. Eng. Technol. 3(4): 374-387

[21] Garriboli L and Jannello A M 2013 Fracture of a popliteal nitinol stent: case report and review of the literature. EJVES Extra 25(3): e15-e17

[22] Bukala J, Kwiatkowski P and Malachowski J 2016 Numerical analysis of stent expansion process in coronary artery stenosis with the use of non-compliant balloon. Biocybern. Biomed. Eng. 36(1): 145-156

[23] Conway C et al 2014 Modelling of atherosclerotic plaque for use in a computational test-bed for stent angioplasty. Ann. Biomed. Eng. 42(12): 2425-2439

[24] Mchugh P, Barakat A and Mcginty S 2016 Medical stents: state of the art and future directions. Ann. Biomed. Eng. 44(2): 274-275

[25] Harewood F et al 2011 A multiscale approach to failure assessment in deployment for cardiovascular stents. J. Multisc. Model. 2(1-2): 1-22

[26] Chen M C Y, Lu P C, Chen J S Y and Hwang N H C 2005 Computational hemodynamics of an implanted coronary stent based on three-dimensional cine angiography reconstruction. ASAIO J. 51(4): 313-320

[27] Gundert T J, Marsden A L, Yang W, Marks D S and LaDisa J F 2012 Identification of hemodynamically optimal coronary stent designs based on vessel caliber. IEEE Trans. Biomed. Eng. 59(7): 1992-2002

[28] Chiastra C 2013 Numerical modeling of hemodynamics in stented coronary arteries. Ph.D. thesis, Politechnico Di Milano, Italy, p. 224

[29] Walker A M, Johnston C R and Rival D E 2012 The quantification of hemodynamic parameters downstream of a Gianturco Zenith stent wire using newtonian and non-newtonian analog fluids in a pulsatile flow environment. J. Biomech. Eng. 134(11): 111001

[30] Kabinejadian F, Ghista D N, Su B, Kaabi Nezhadian M, Chua L P, Yeo J H and Leo H L 2014 In vitro measurements of velocity and wall shear stress in a novel sequential anastomotic graft design model under pulsatile flow conditions. Med. Eng. Phys. 36(10): 1233-1245
[31] Martin D M and Boyle F J 2015 Sequential structural and fluid dynamics analysis of balloon-expandable coronary stents: a multivariable statistical analysis. Cardiovasc. Eng. Technol. 6(3): 314-328

[32] Pant S, Bressloff N W and Limbert G 2012 Geometry parameterization and multidisciplinary constrained optimization of coronary stents. Biomech. Model. Mechanobiol. 11(1-2): 61-82

[33] Pant S, Limbert G, Curzen N P and Bressloff N W 2011 Multiobjective design optimisation of coronary stents. Biomaterials 32(31): 7755-7773

[34] Mani G, Feldman M D, Patel D and Agrawal C M 2007 Coronary stents: a materials perspective. Biomaterials 28(9): $1689-1710$

[35] Dodge J T, Brown B G, Bolson E L and Dodge H T 1992 Lumen diameter of normal human coronary arteries. Influence of age, sex, anatomic variation, and left ventricular hypertrophy or dilation. Circulation 86(1): 232-246

[36] Murphy B P, Savage P, McHugh P E and Quinn D F 2003 The stress-strain behavior of coronary stent struts is size dependent. Ann. Biomed. Eng. 31(6): 686-691

[37] Douglas G R, Phani S A and Gagnon J 2014 Analyses and design of expansion mechanisms of balloon expandable vascular stents. J. Biomech. 47(6): 1438-1446

[38] Chan W, Ding Y and Tu J 2007 Modeling of non-Newtonian blood flow through a stenosed artery incorporating fluidstructure interaction. ANZIAM J. 47: 507-523

[39] Gundert T J, Marsden A L, Yang W and LaDisa J F 2012 Optimization of cardiovascular stent design using computational fluid dynamics. J. Biomech. Eng. 134(1): 011002

[40] Ladisa J F, Guler I, Olson L E, Hettrick D A, Kersten J R, Warltier D C and Pagel P S 2003 Three-dimensional computational fluid dynamics modeling of alterations in coronary wall shear stress produced by stent implantation. Ann. Biomed. Eng. 31(8): 972-980

[41] Migliavacca F, Petrini L, Montanari V, Quagliana I, Auricchio F and Dubini G 2005 A predictive study of the mechanical behaviour of coronary stents by computer modelling. Med. Eng. Phys. 27(1): 13-18

[42] Koskinas K C, Chatzizisis Y S, Antoniadis A P and Giannoglou G D 2012 Role of endothelial shear stress in stent restenosis and thrombosis pathophysiologic mechanisms and implications for clinical translation. J. Am. Coll. Cardiol. 59(15): 1337-1349

[43] Davies J E, Whinnett Z I, Francis D P, Manisty C H, Aguado-Sierra J, Willson K, Foale R A, Malik I S, Hughes A D, Parker K H and Mayet J 2006 Evidence of a dominant backward-propagating 'suction' wave responsible for diastolic coronary filling in humans, attenuated in left ventricular hypertrophy. Circulation 113(14): 1768-1778

[44] Martin D M, Murphy E A and Boyle F J 2014 Computational fluid dynamics analysis of balloon-expandable coronary stents: influence of stent and vessel deformation. Med. Eng. Phys. 36(8): 1047-1056

[45] Murphy J B and Boyle F J 2010 A numerical methodology to fully elucidate the altered wall shear stress in a stented coronary artery. Cardiovasc. Eng. Technol. 1(4): 256-268

[46] Azaouzi M, Makradi A, Petit J, Belouettar S and Polit O 2013 On the numerical investigation of cardiovascular balloon-expandable stent using finite element method. Comput. Mater. Sci. 79: 326-335 
[47] Kanaris A G, Anastasiou A D and Paras S V 2012 Modeling the effect of blood viscosity on hemodynamic factors in a small bifurcated artery. Chem. Eng. Sci. 71: 202-211

[48] He Y, Duraiswamy N, Frank A O and Moore J E 2005 Blood flow in stented arteries: a parametric comparison of strut design patterns in three dimensions. J. Biomech. Eng. 127(4): 637-647

[49] Dumoulin C and Cochelin B 2000 Mechanical behaviour modelling of balloon-expandable stents. J. Biomech. 33(11): $1461-1470$ 